\title{
Proposal of an Instructional Design for Teaching the Requirement Process for Designing Information Systems
}

\author{
Yuka Kato and Yukio Namba \\ Advanced Institute of Industrial Technology \\ Shinagawa-Ku, Tokyo, Japan
}

yuka@aiit.ac.jp; namba-yukio@aiit.ac.jp

\begin{abstract}
Both industry and education struggle to foster the development of human resources who can manage and design information systems at an advanced level. Human resources, particularly within the field of business modeling, must develop the competency to conduct business in the real world. Determining how to foster compet ent human resources is an urgent and important issue for all educational programs but especially for professional graduate school programs in information systems.

This paper presents the results of our analy sis of a seminar aimed at teaching the conceptual data modeling needed for developing a business structure in the real world. The authors discuss the effectiveness and implications of applying this method to gain comprehension of the objective business domain and acquire skills derived though the learning process.
\end{abstract}

Keywords: information systems, requirement, architect, learning process, concept ual data modeling, competency, team learning, instructional design

\section{Introduction}

In the field of information systems (IS) design, the requirement process and related fields are growing in importance. Despite their importance, the development of human resources in these fields does not appear to be proceeding in tandem with their requirements. It is urgent that both industry and education focus on fostering human resources who can direct the requirement and design processes of information systems.

For systems vendor companies, the development of high value-added systems analysts and architects has become a critical measure to survive and cope with rival foreign companies who provide cheaper systems. For systems user companies, fostering human resources with capabilities and skills has become a strategic issue.

Material published as part of this publication, either on-line or in print, is copyrighted by the Informing Science Institute. Permission to make digital or paper copy of part or all of these works for personal or classroomuse is granted without fee provided that the copies are not made or distributed for profit or commercial advantage AND that copies 1 ) bear this notice in full and 2) give the full citation on the first page. It is permissible to abstract these works solong as credit is given. To copy in all other cases or to republish or to post on a serveror to redistribute to lists requires specific permission and payment of a fee.Contact Publisher@ InformingScience.org to request redistribution permission. These capabilities and skills include the ability to elaborate an enterprise information systems architecture that matches the business structure and determine system requirements and specifications for individual systems based on the enterprise architecture. Japanese government and industry have advocated a proposal (Information Service and Software Sub-committee, 2007) to promote the fostering of IT human re- 
sources at an advanced level. Figure 1 shows the relationship between the levels of required human resources of this proposal and our target discussed later in this article.

This proposal classifies IT human resources into seven levels. Level one is the entry level, levels two and three correspond to the middle levels, and levels four to seven correspond to the advanced level. The critical issue is how to raise human resources to at least level five.

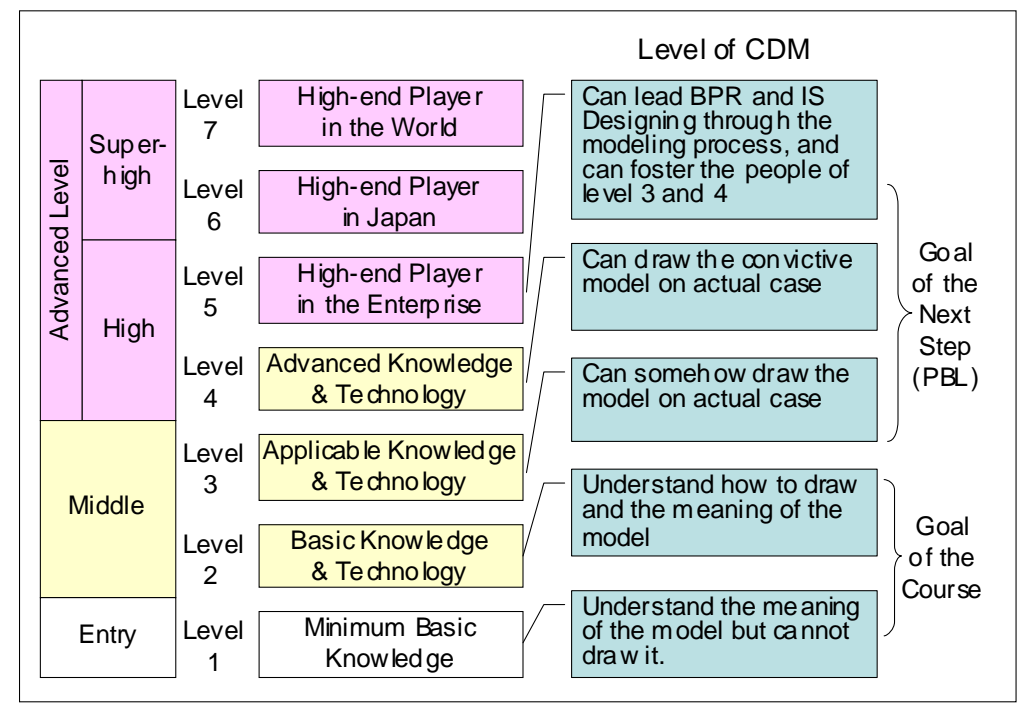

Figure 1. Relationship of the Skill Levels between Proposal \& Course

The first step in developing information systems involves shaping business activities in the targeted domain as requirements. After the desired outcomes are described to them, architects must have the competencies to analyze and map business structures and processes into an information system. The human resources who take charge of this field should have the ability to understand and describe business structure in the targeted domain as well as in information systems.

In addition to standard data-based education, education based on experience may be required to develop human resources. Many researchers claim that on-the-jobtraining (OJT) is suitable for this purpose. Although many companies apply OJT, much of the training does not succeed because of a lack of competent instructors. Often, those most suitable to become OJT instructors are busy people who do not have sufficient time to provide training. In consequence, trainees do not receive enough guidance, and thus not enough results, from their training. The means by which to foster capable human resources must be considered an urgent and important issue for educational programs, especially for professional graduate school programs in information systems.

As a part of a program that advances IT human resources, we have implemented a course of business modeling by means of a seminar to foster the human resources described above. This paper describes the design of the learning process and assesses the applicability and effectiveness of the instructional process. 
Kato \& Namba

\section{Describing a Business Structure with Conceptual Data Modeling}

\section{Information Systems Requirements and Conceptual Data Modeling}

The first issue in developing information systems is determining how to design the system according to client requirements. It is necessary to visualize the potential requirements of both clients and business experts in an objective domain. In conjunction with visualization, consensus building between stakeholders, including both clients and information systems architects, is indispensable.

Much research and many studies (e.g. Davis, 2004; Jackson, 1995) have been produced on client requirements. The essential point of the requirement process is inheres how to describe a realworld process. In reality, architects interpret the requirements related to them by business experts because the architects tend not to be familiar with the real-world activities of the systems.

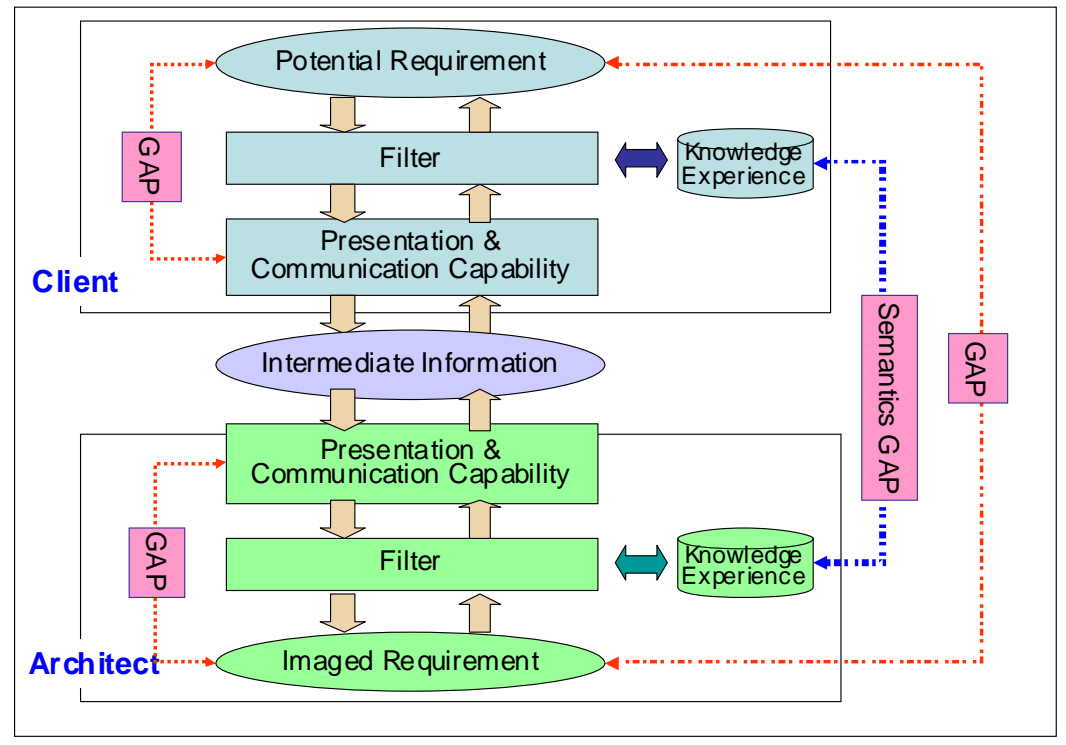

Fig.2 Gaps generated through requirement process

The business experts in this situation may not necessarily comprehend the overall business processes accurately; they may only view the processes from their professional background and personal perspective. Clients, however, have the capacity and vision to grasp the real-world requirements necessary for systems development, as shown in Figure 2. Thus, client requirements can be considered intermediate information that passes through a filter composed of their knowledge and experience and modified by their present ation and communication capabilities. This intermediate information then passes through another filter shaped by the architect's capabilities. When the architect works with many clients, many information gaps are created. The architect must then develop requirements from information distorted by these gaps.

\section{Conceptual Data Modeling}

Teshima, Koike, and Endo (1994) insists that information systems with stable structures can be built by applying the conceptual data modeling that maps a business structure into the information system as a dat a model. Conceptual dat a modeling originated from the ANSI/SPARC threelevel schema concept to describe the structure of the real world (Universe of Discourse). Te- 
shima and the Manufacturing Architecture for Series Production (MASP, 2007) Association applied this concept to analyze the business structure and describe it as a data model. They then refined this methodology and named it the concept ual data modeling method (CDM). When many companies, including KDDI (Namba, 2007) and JFE Steel (Owada, 2006), applied this method to rebuild their information systems, they received the anticipated results. The structure and characteristics of the objective world in which people are commonly interested can be described as a conceptual data model.

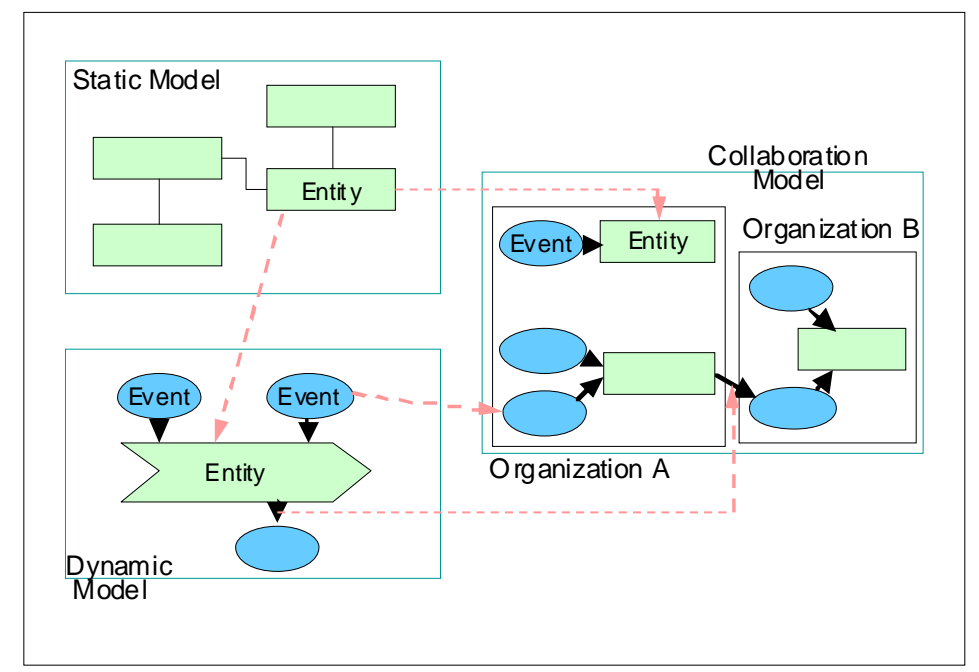

Figure 3. Relationship between three models of Conceptual Data-model

When we describe the structure of a business in a conceptual data model, we use three types of models: the static, dynamic, and collaboration models. The static model, which describes the nature of entities and the relationship among them, can be described by the entity relationship diagram (ERD). The dynamic model shows states of transitions of entities by describing the behavior of events. The collaboration model represents the relationship between entities and events generated in the logical organization. Figure 3 shows the relationship bet ween three models of the conceptual data-model.

\section{Course Design}

Until now, the authors have designed the CDM instructional process and evaluated the educational results (Namba \& Kato, 2007). Advancing further in our work, the process was revised and improved based on the results in this section. Since the goal of the course is successful student achievement at skill levels 1 and 2 (see Figure 1), it was designed according to these levels as a pre-stage to achieve an advanced level.

\section{Design Concept}

The targets of the course were students studying information systems at a professional school. The course consisted of 14 units taught in 90-minute classes twice a week for about 8 weeks. The purpose of this section is to design the content of these 14 units. In 2006, we decided on the subject "Major business functions of the institutional administration office" because at a professional school, it is necessary that almost all students could easily understand and investigate the business. The instructional method was that of a team-based study in which each team had 7 or 8 members. In the 2006 version of the course, the instruct ors selected documents to produce and provided a rough schedule based upon which the students determined a concrete process of modeling. Presentations of products (i.e., product reviews) were held at the midpoint and the end of 
the course. The student teams submitted the products (the documents of 3 models and Japanese descriptions) to the instruct ors at the same time. Based on the products submitted and results of a questionnaire survey completed after the course ended, the authors concluded that the members of all the teams had acquired the competency necessary for conceptual dat a modeling. At the same time, we determined that more detailed research into the following is needed to educate students more efficiently in a course that only has limited time for instruction:

- The team members consisted of students who were not part of a hierarchy. Therefore, team ranking was determined by random chance rather than individual characteristics. As a result, the particular grouping of members impeded team activities in some teams.

- For acquiring expertise, reflection on past conduct and awareness are very important. The combination of members affected these factors, and acquired levels of expertise differed greatly among teams.

- Although various levels of students took the course, we had the students determine a concrete process of modeling. Consequently, the educational effect varied widely among the teams.

- An evaluation of the learning process is very import ant for a course whose purpose is to acquire expertise, but an evaluation was not possible for this course because learning process records were not available except within the review times.

To resolve these problems, we developed the following four design concepts for the instructional process:

- Assign three explicit roles within each team for improving team activities. These three roles are that of a facilitator, a team member in charge of proceedings, a team member in charge of products and modelers. During the 2006 course, frequent arguments among team members impeded team progress. Having one team member remain in charge of proceedings and record the proceedings of all meetings prevented impediments to progress.

- Manage the revisions of documents as well as the proceedings. This makes it easier to follow the discussion process and encourages reflection and awareness.

- Design a more effective instructional process based on competencies by identifying and following the learning process. According to the three-grade model of acquiring expertise for ICT education (Inoue \& Kaneda, 2007), a scenario-based study is suitable for various levels of learners. Therefore, we designed a detailed course-learning process with projects for each unit.

- Submit the proceedings and information on all of the products still in progress at each meeting to evaluate the learning process.

\section{The Learning Process}

When designing the instructional process, we determined that the following 9 learning steps of CDM education will lead to the most beneficial outcomes:

(1) Students are able to describe CDM diagrams with the correct notation.

(2) Students are able to find "core entities" and "core events" while modeling.

(3) Students are able to determine suitable "identifier" and main attributes to identify core entities.

(4) Students are able to refine a static model with referenceto Japanese descriptions.

(5) Students are able to refine a static model with referenceto a dynamic model.

(6) Students are able to refine a static model with referenceto a collaboration model. 
(7) Students are able to find essential entities and the relationship among them by considering correlation among 3 models.

(8) Students are able to find contradiction and inconsistency of the models while describing 3 models in sequence and to refine them.

(9) Students are able to grasp business architecture of the modeling target by using CDM.

By following these steps, students will acquire an understanding of the appropriate manner in which to approach CDM, grasping business architecture modeling at an enterprise level from a macro point of view, and learn how to conduct business within unknown industries. In addition, students will develop their project management, presentation and communication.

\section{The Instructional Process}

We designed the instructional time units based on the learning steps. The authors decided upon "Major business functions of the institutional library" as the subject because users of the library, students could easily understand the business and obtain interviews with the librarians. Additionally, the business scale, with an estimated 20 to 30 entities, would be suit able for our course. We divided the students into 7 teams of 7 or 8 students each. The following is a listing of the topics and activities planned for each unit:

$1^{\text {st: }} \quad$ Introduction, grouping

$2^{\text {nd }}: \quad$ Static model (1) (ERD)

$3^{\text {rd }}$ : Interview (1) (with the librarian)

$4^{\text {th }}$ : Static model (2) (ERD, descriptions)

$5^{\text {th }}: \quad$ Dynamic model (1)

$6^{\text {th }}: \quad$ Dynamic model (2)

$7^{\text {th }}$ : The first review

$8^{\text {th }}$ : Collaboration model

$9^{\text {th }}: \quad$ Interview (2) (with the librarian)

$10^{\text {th }}:$ Refine all models (1)

$11^{\text {th }}$ :Refine all models (2)

$12^{\text {th }}$ :Refine all models (3)

$13^{\text {th }}$ :Final review

$14^{\text {th }}$ :Conclusion

The followings are the special features we designed for the course:

- We clarified the modeling process and designed the units in detail according to the learning steps.

- We indicated the modeling process to students in advance and presented the topic at each unit.

- We prepared thetemplate files of three diagrams so that the students could work efficiently. These templates were also helpful for examining work items and estimating workload.

- We required the teams to record all the proceedings of meetings whenever they were working, including during extra hours outside of class, and required them to submit all of the products still in progress.

- We described the roles of the following team members clearly and concretely:

- Facilitat or: A team member who organizes discussions. 
- Person in charge of proceedings: A team member who records the proceedings of meetings and reviews the previous proceedings to prevent team members from repeatedly bringing up the sametopics.

- Person in charge of products: Ateam member who updates the models as the team progresses and conducts revision management.

Except for four or five members, the three roles worked well for modeling. Because team members took turns assuming these roles, all of the students gained experience in all of the roles. This was necessary because the purpose of the course was to allow st udents to acquire the competencies necessary for becoming information system architects. These competencies include facilitating work among business experts, reporting the proceedings, and constructing the models.

\section{Evaluation}

\section{Evaluation Metrics}

In this section, the instructional process is evaluated. The level of the learning process that was acquired in each unit could be grasped based upon the documents and proceedings submitted in every unit by the teams. In this paper, we investigate the beginning and ending units of learning for each step by using them. There is a possibility that not all of the steps that needed to be acquired remained at the end of the course. Our goal was to decrease the number of the steps. With that purpose in mind, we analyzed the results, investigated which competencies were difficult to acquire, and reviewed and refined the instructional process.

\section{Evaluation Results}

\section{Comparison among teams}

First, we analyzed the transition of the number of entities to compare the feat ures among the teams. Figure 4 shows the comparison results. In general, there is a tendency to acquire a large number of entities at the beginning and then focus on the appropriate number by considering the viewpoint of "core entities." After this process, some entities are added to the model for deepening their understanding of the target business through the first review and the interviews. Figure 4 shows that because five teams indicated almost the sametransition patterns, little diversity existed among the teams. On the other hand, the numbers of team 3 and team 6 transit specifically, so their leaming process was different from that of the other teams. We, therefore, analyzed the feat ures of the teams in detail.

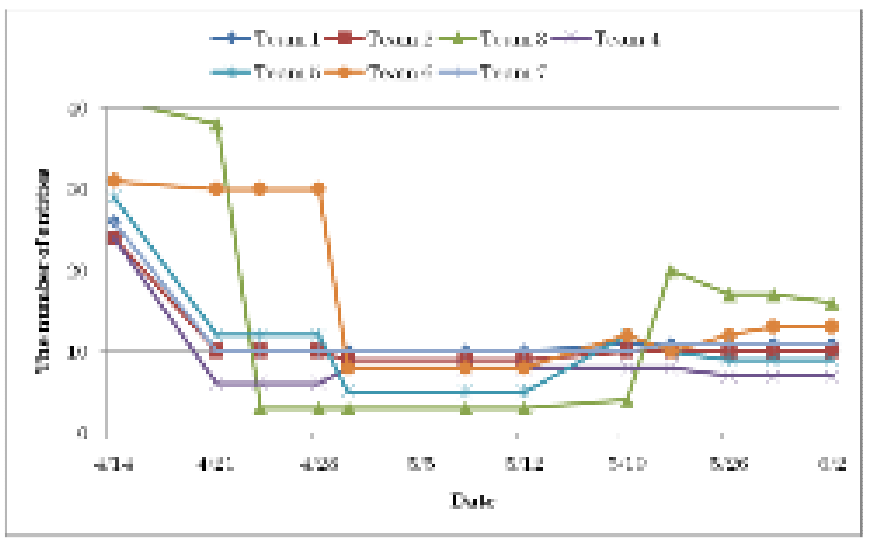

Figure 4. The transition of the number of entities 
At the end of the course, we conducted mutual assessment among the team members to evaluate the contribution of each memberto the team. We required each member to select the member of his or herteam who had contributed the most to the team's progress. In this analysis, we investigated the assessment results and the number of learning steps acquired at the end of the course for each team. Table 1 shows the results. The mutual assessment value is the standard deviation of team members' scores in a team. A large value means that some members took leadership roles whereas a small value means that all of the members contributed equally or a split occurred among the members. T wo types of members achieved good mutual assessment result. One type of member led the team and the other type greatly supported the team's work. Although these are completely different roles, they were not classified in this paper. The number of acquired steps expresses the grades of a team.

Table 1. Anal ysis Resul ts

\begin{tabular}{|c|c|c|c|c|c|c|c|c|c|c|c|}
\hline Team & $\begin{array}{l}\text { Mutual as- } \\
\text { sessment }\end{array}$ & $\begin{array}{l}\text { No. of acquired } \\
\text { steps }\end{array}$ & (1) & (2) & (3) & (4) & (5) & (6) & (7) & (8) & $(9)$ \\
\hline 1 & 1.91 & 6 & $\bar{O}$ & $\mathrm{O}$ & $\mathrm{X}$ & $\mathrm{O}$ & $\bar{O}$ & $\mathrm{X}$ & $\mathrm{X}$ & $\bar{O}$ & 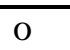 \\
\hline 2 & 4.31 & 9 & $\mathrm{O}$ & 0 & 0 & 0 & 0 & 0 & 0 & $\mathrm{O}$ & 0 \\
\hline 3 & 3.09 & 4 & 0 & $\mathrm{O}$ & $\mathrm{X}$ & $\mathrm{O}$ & $\mathrm{X}$ & $\mathrm{X}$ & $\mathrm{X}$ & $\mathrm{X}$ & 0 \\
\hline 4 & 3.06 & 8 & $\mathrm{O}$ & 0 & $\mathrm{O}$ & $\mathrm{O}$ & 0 & $\mathrm{X}$ & $\mathrm{O}$ & o & 0 \\
\hline 5 & 1.27 & 8 & $\mathrm{O}$ & 0 & 0 & o & 0 & 0 & $\mathrm{X}$ & $\mathrm{O}$ & 0 \\
\hline 6 & 3.43 & 2 & o & $\mathrm{x}$ & $\mathrm{x}$ & 0 & $\mathrm{X}$ & $\mathrm{X}$ & $\mathrm{X}$ & $\mathrm{X}$ & $\bar{x}$ \\
\hline 7 & 3.55 & 7 & $\bar{O}$ & o & O & O & o & $\mathrm{X}$ & $\mathrm{X}$ & $\bar{O}$ & 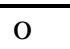 \\
\hline
\end{tabular}

Table 1 indicates that the transition of the number of entities is not affected by the value of the mutual assessment but is affected by the number of acquired steps. This result means that the educational effect does not depend on the feat ures of teams but does not depend greatly on the acquired steps and conditions of the learning process. An appropriate design of the instructional process is required. In particular, the acquired conditions of "step (3)" and "both of step (6) and (7)" greatly affected the outcomes: therefore, we should concentrate on these steps as a guide. Next, we analyzed the relationship between the instructional process and the acquired conditions of the learning steps.

\section{Evaluation of the learning steps}

To analyze the acquisition process of the learning steps, we investigated the number of teams in learning along a time series by each step. The results are shown in Figure 5. The vertical ax is is the number of teams in learning and the horizontal axis is the units of the course. Since the value at the $14^{\text {th }}$ unit is the number of teams not acquiring the result at the end of the course, we concluded that the instructional process should be designed so that the value is zero until a certain period in time. In this case, the acquired levels of step (3), (6), and (7) were not sufficient. Many students failed in CDM learning at these steps, and we therefore need to redesign the instructional process. For step (3), although the beginning time is at an early stage, it takes much time to acquire the result. Moreover, this step affects the acquisition process for the other steps. For steps (6) and (7), since the beginning time is at a relatively late stage, earlier learning is required. 

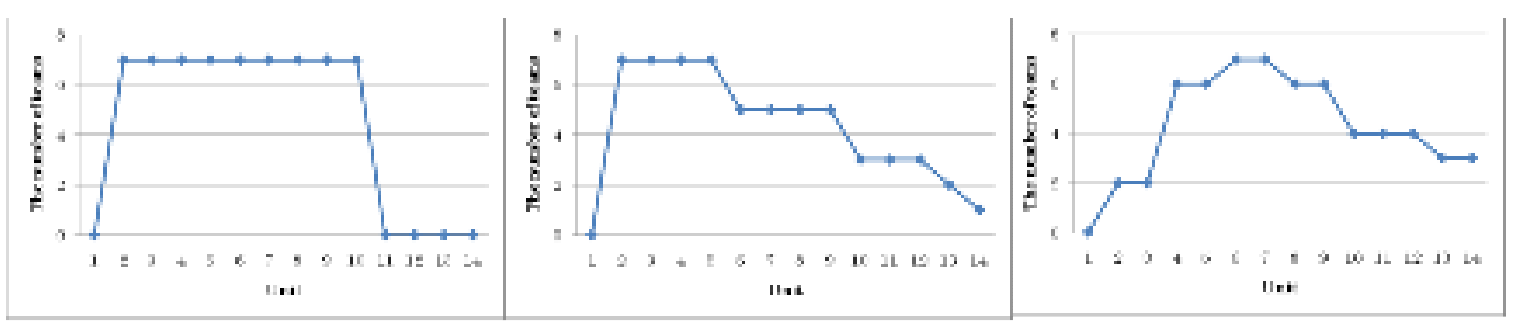

Step (1)

Step (2)

$\operatorname{Step}(3)$
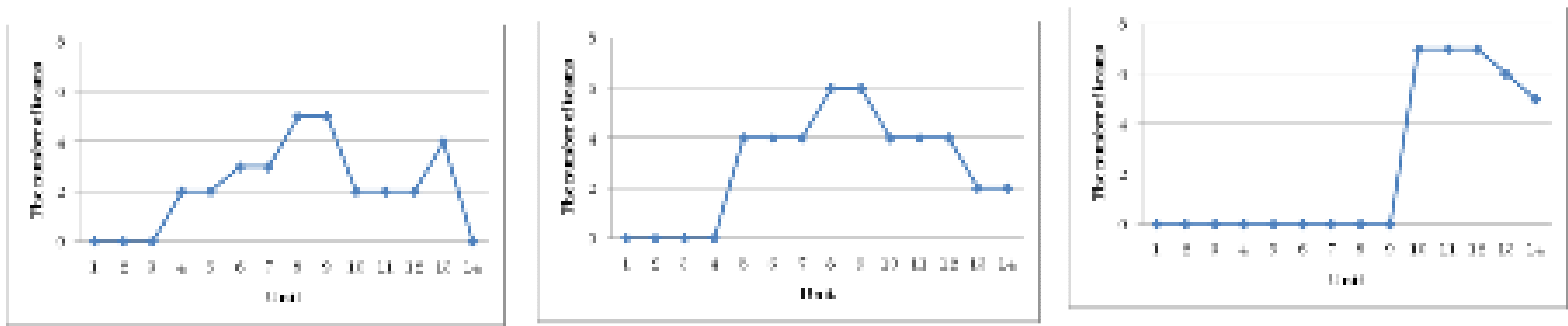

Step (4)

Step (5)

Step (6)
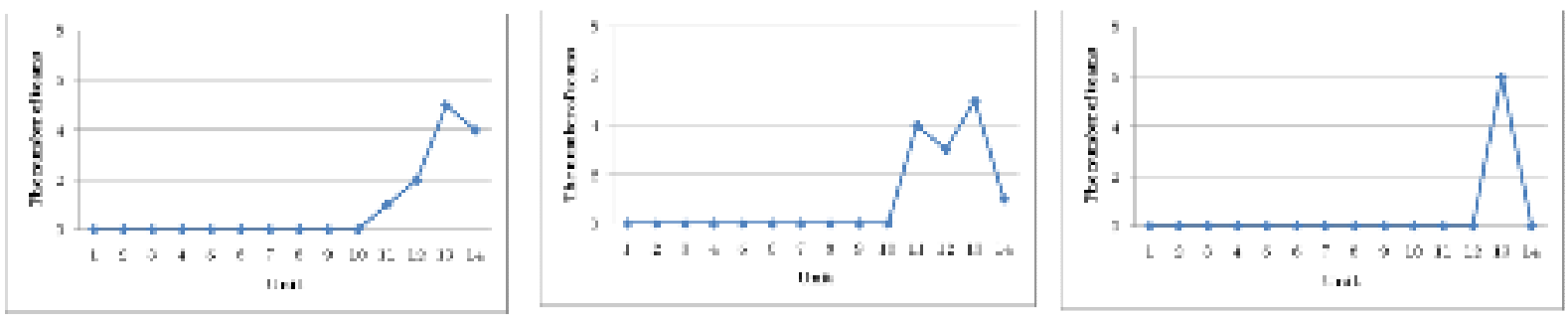

Step (7)

Step (8)

Step (9)

Figure 5. The number of teams in learning (by each step)

\section{Comparison between 2006 and 2007}

In 2007, the authors refined and redesigned the instructional process. More specifically, we clarified the instructional units, determined the roles of team members, and recorded the proceedings. To evaluate the redesign process, we investigated the transition of the number of entities in 2006 and 2007. In 2006, the products at the first review ( $10^{\text {th }}$ unit) and final review were available. Therefore, we compare the numbers at the $10^{\text {th }}$ and $14^{\text {th }}$ units (the final products). Figure 6 shows the result. 


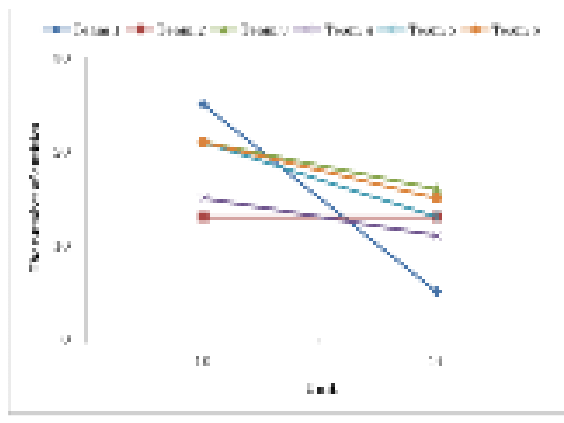

2006

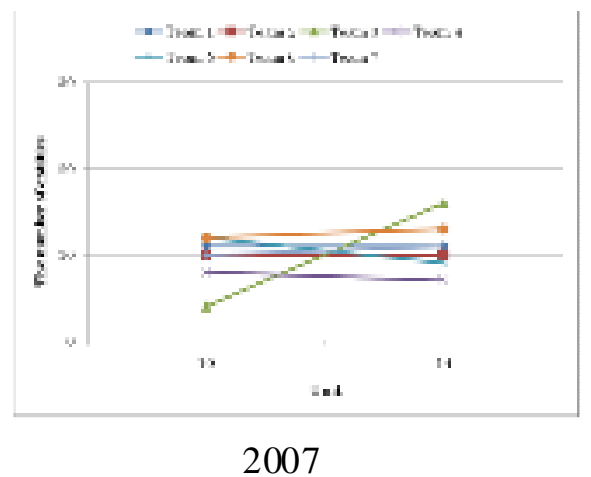

2007

Figure 6. The transition of the number of entities

The followings are the standard deviations of the number of entities:

- 2006 At the $10^{\text {th }}$ unit: 4.07 , at the $14^{\text {th }}$ unit: 3.58

- 2007 At the $10^{\text {th }}$ unit: 2.61 , at the $14^{\text {th }}$ unit: 2.67

These results indicate that the appropriate number of entities had not been determined by the $10^{\text {th }}$ unit in 2006. The authors found that the argument was frequently repeated, impeding progress. In addition, the authors found that the acquired conditions of expertise varied widely in 2006. On the other hand, the determination of ent it ies was almost terminated at the $10^{\text {th }}$ unit in 2007, and acquired conditions varied relatively little. These results show the effects of the refinement and redesign of the course.

\section{Discussion of Assessment of Competency}

There has been much discussion on how to assess a competency that students acquire objectively, as well as what data and/or information should be collected and how it should be evaluated, processed, and provided for third party assessment.

The U.S. Department of Education (2002) defined a competency as "a combination of skills, abilities, and knowledge needed to perform a specific task." According to Bers (2001), "Information about the quality and range of competencies needs to be available and communicated in meaningful, useful terms to a variety of audiences.... There are two broad audiences... the first is an internal audience, including students, faculty, and staff. The second broad audience is external, including state higher education agencies, accrediting organizations, and professional associations, as well as groups out side of education."

For working students attending a professional school, a high value should be attached to assessment for external audiences. Some metrics that can assess competency objectively are necessary to be able to discuss how much students have improved through the coursework. The authors have been trying to develop these metrics for two years. The authors have been striving to produce quantitative information about the items for which results can be expressed numerically and qualitative information about the items that cannot be expressed numerically.

Our assessment shows that the students reached some level of the following competencies:

- Describe the conceptual data model in three manners.

- Understand the identifier and major attributes.

- Underst and the relationship between the three models and review each model.

- Gain a certain amount of perspective on the structure of business through modeling.

- Identify organizational issues through modeling. 
As for an assessment of competency toward an external audience, the authors believe that a lead on the direction has been gained by the results of this analysis.

Our methodology will become a potent assessment technique if we can map it to the skill levels of various skill standards. In Japan, the IT skill standards that had been divided into three standards_-Skill Standards for IT Professionals (IT SS), used mainly for vender companies, Users' Information Systems Skill St andards (UISS), and Embedded Technology Skill Standards ET SS - have been unified. Metrics that assess competency would be require d together with this unification.

\section{Lessons Learned}

The authors completed the coursework on conceptual dat modeling by means of a seminar this year followed up to last year. We could not assess the instructional process for last year's coursework because of a lack of knowledge and experience. This year, we changed some instructional processes by utilization of the lessons that we learned last year. This section describes the lessons we learned from the instructional process.

Tracking the learning process of the students, such as the proceedings and each version of products produced, is valuable when analyzing the process. However, analyzing the instructional process is time consuming and requires both the development of tools for analy sis and assessment techniques.

Two major findings resulted from the process assessment. One is that role sharing in teams, especially recording the proceedings, decreased the amount of time required to complete the model compared to the time required last year. Many teams remained at a rather low level just before the final presentation last year. This year, more than a few teams could go to the model refining stage at an earlier stage compared to last year. The differences in the product levels among the teams this year were less than they had been last year.

The second finding was that the changes needed to improve the coursework became clear. Two major issues must be considered to improve the coursework;

- Comprehension relevant to identifier, granularity of entities, and viewpoint is critical for the students to learn conceptual data modeling. Developing an instructional process that supports the learning of these points is required.

- Some teams could not examine each model in conjunction with the other models because they could barely understand the collaboration model. Although we scheduled the collaboration model on and after the eighth unit, students still had trouble understanding the model. More time is required for the process of refining and exploiting the three models.

We will continue to review the instructional processes over time and leverage the instructional design for the next year.

Reviewing the instructional process should be required. Some instructional steps required many units whereas others only required one unit. This can be attributed to the differences in the difficulty of the steps; some were more difficult whereas others were easier for the teams. Redefinition of the instructional processes is required by improving time allocation and merging or splitting the instructional process. It may be effect ive to give a concrete explanation of the contents within a proper amount of time. If we could prepare the template to draw a diagram of the model, the time unit for the modeling method would not be necessary. As some teams had problems understanding the collaboration model, we must prepare a more detailed process definition for such a process as understanding the logical organization. These considerations may balance the load of each time unit. 
There was little difference in the advancement of learning between the teams with strong leadership and those with weak leadership. We compiled teams randomly. It may have been correct to form teams by random if the relationship among the team members had not affected the performance of the instruction.

The transition of the number of entities for each time unit shows the same trend of the thinking process of all students except two teams. When we analyzed the characteristics of these teams according totime and products, we realized that these discrepancies related to the degree of completion of each learning process. In other words, teams with inefficient learning showed a peculiar pattern. Although we will continue to attempt to clarify this discrepancy, we may alter the kind of team with strong instruct or support if we can identify these trends at an early stage.

The gaps originating from communication and cognition that are shown in Figure 2 would be closed considerably if the recommendations in this article are followed. Gaps of cognition toward the object could be dissolved through discussion with the aid of visual models. The amount of understanding of the real-world business structure through models is proportional to the degree of completion of the models.

\section{Conclusion}

The authors designed the coursework for business modeling, the first step in building information systems, and implemented it over two years. Because the second-year course exploited the lessons learned during the first year, we could improve the performance of the coursework. Both the time required for the modeling work and the version control of the products, such as modeling diagrams, for every project are effective for analyzing the learning process. Additional issues that can improve the learning process emerged during the analysis process. The authors would like to leverage this information to design the next course.

We did not demonstrate concretely how we could affect the competency that the students acquired to audiences outside of the school. However, we can view the direction to compose a practical metrics based on the analysis of this study. We would like to design the metrics and evaluate them in the next course.

The learners in this course are those who have knowledge and experience in information systems but not in business in the objective domain. The conceptual data modeling that is the theme of this course is effective in allowing people to view the global picture and understand business structures and processes in the domain. The subject of future investigations should be how to apply the result s of concept ual data modeling to the design and development processes of information systems. The authors would like to apply these ideas to a project-based learning theme for second- year students as well.

\section{References}

Bers, T. H. (2001). Measuring and reporting competencies. In R. A. Voorhees (Ed), Measuring what matters. Jossey-Bass.

Davis, A. M. (2004). Just enough requirements management. Dorset House Publishing.

In formation Service and Software Sub-committee, Inform ation Economy Committee, Industrial Structure Council. (2007). Report of the Human Resources Development Working Group. Retrieved November 4, 2007, from http://www.meti.go.jp/press/20070720006/03 houkokusho.pdf

Inoue, A., \& Kaneda, S. (2007). A PBL approach using real world application development between university and local government. IPSJ SIG Technical Report 2007-IS-99, 115-122.

Jackson, M. (1995). Software requirement \& specification: A exicon of practis, principles and prejudice, ACM Press. (Japanese Translation). 
Kato \& Namba

MASP. (2007). Retrieved November 1, 2007, from http://www.masp-assoc.org/

Namba, Y. (2007). City planning approach for enterprise information systems. Bulletin of Advanced Institute of Industrial Technology, 1, 39-48.

Namba, Y., \& Kato, Y. (2007). A trial for education on the upper portion of the design process for information systems. Bulletin of Advanced Institute of Industrial Technology, 1, 39-48.

Owada, N. (2006). Challenge to the system to adapt to change with spending one year for data modeling, Nikkei Computer, 5(1), 132-137.

Teshima, A., Koike, T. \& Endo, S. (1994) Downsizing of software by conceptual data modeling. JMA Management Center.

U.S. Department of Education. (2002). Defining and assessing learning: Exploring competency-based initiatives. Retrieved from http://nces.ed.gov/pubs2002/2002159.pdf

\section{Biography}

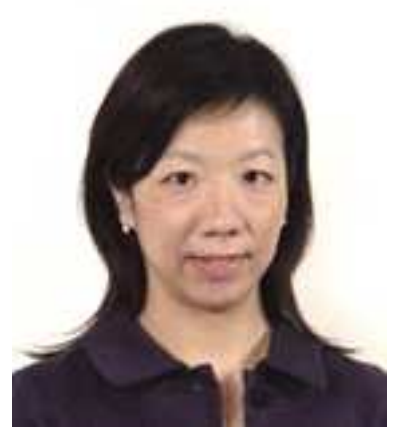

Yuka Kato is an Associate Professor of School of IndustrialTechnology, Advanced Institute of Industrial Technology, Japan. Her research interests include computer net works and distributed multimedia systems. She received her Ph.D degree in Information Systems from the University of Electro-Communications, Japan.

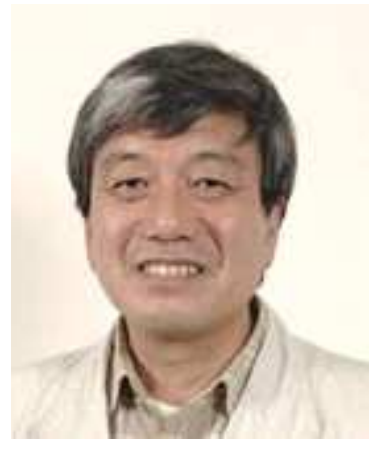

Yukio Namba is a Professor of School of Industrial Technology, Advanced Institute of Industrial Technology, Japan. His research interests include enterprise information systems architecture and conceptual data modeling. He received his $\mathrm{Ph}, \mathrm{D}$ degree from the Graduate School of Science and Engineering, Tokyo Institute of Technology. 